\title{
Optimization of heterologous protein production in Chinese hamster ovary cells under overexpression of spliced form of human X-box binding protein
}

\author{
Galina Gulis, Kelly Cristina Rodrigues Simi, Renata Rodrigues de Toledo, Andrea Queiroz Maranhao \\ and Marcelo Macedo Brigido
}

\begin{abstract}
Background: The optimization of protein production is a complex and challenging problem in biotechnology. Different techniques for transcription, translation engineering and the optimization of cell culture conditions have been used to improve protein secretion, but there remain many open problems involving post-translational modifications of the secreted protein and cell line stability.

Results: In this work, we focus on the regulation of secreted protein specific productivity (using a recombinant human immunoglobulin $\mathrm{G}(\mathrm{IgG})$ ) by controlling the expression of the spliced form of human X-box binding protein (XBP-(s)) in Chinese hamster ovary cells (CHO-K1) under doxycycline (DOX) induction at different temperatures. We observed a four-fold increase in specific IgG productivity by $\mathrm{CHO}$ cells under elevated concentrations of DOX at $30^{\circ} \mathrm{C}$ compared to $37^{\circ} \mathrm{C}$, without detectable differences in binding activity in vitro or changes in the structural integrity of IgG. In addition, we found a correlation between the overexpression of human XBP-1(s) (and, as a consequence, endoplasmic reticulum (ER) size expansion) and the specific lgG productivity under DOX induction.
\end{abstract}

Conclusions: Our data suggest the T-REX system overexpressing human XBP-1(s) can be successfully used in CHO-K1 cells for human immunoglobulin production.

Keywords: $\mathrm{CHO}$ cells, Heterologous protein production, X-box binding protein, T-REX ${ }^{\mathrm{TM}}$ system, Doxycycline

\section{Background}

The optimization of the production of secreted proteins, such as therapeutic monoclonal antibodies (mAbs), is still a challenging problem in pharmaceutical biotechnology. Although biopharmaceutical products can be produced by many host cell systems, eukaryotic cells are preferred due to their ability to correctly process and modify human proteins. The primary goal is to establish the ideal combination of a rapid accumulation of productive biomass and the maintenance of cell viability for as long as possible. Many different strategies have been considered for improving both cell viability and the productivity of recombinant proteins, including mAbs. These strategies include physiological optimization and genetic and metabolic engineering $[1,2]$.

\footnotetext{
* Correspondence: gulis001@gmail.com

Institute of Biological Sciences, Department of Cell Biology, University of Brasilia, Campus Universitário Darcy Ribeiro, Brasília, DF 70910-900, Brazil
}

The most common problem during the optimization of protein production is an error in protein folding in the endoplasmic reticulum (ER). The inhibition of protein folding activates the unfolded protein response (UPR), which is a signal transduction network. Overcoming UPR is one of the many strategies for optimizing protein productivity. For instance, protein production has been tested under the expression of survival proteins that play important roles in UPR, including B-cell lymphoma protein 2 (bcl-2), B-cell lymphoma-extralarge protein (bcl-XL) [3-5], caspase inhibitors [6] and molecular chaperones/heat shock proteins (HSP70) [7]. The role of the spliced form of X-box binding protein (XBP-1(s)) (which plays an important role in regulation processes, such as physical expansion of the ER, increasing the mitochondrial mass and function, increasing the cell size and enhancing total protein synthesis) in optimizing protein production has also been studied [8]. 
This approach to increasing the secretion capacity of mammalian cells by overexpressing the transcription factor XBP-1(s) was successful in $\mathrm{CHO}$ cells; the production of the secreted proteins alkaline phosphatase (SEAP) and alpha-amylase (SAMY) was enhanced upon XBP-1(s) overexpression [9], as was the production of antibody [10]. However, these studies have shown that using overexpression systems without regulation leads to cell apoptosis due to the accumulation of the produced proteins [11].

To overcome accumulation-induced apoptosis, other strategies have been applied to regulate the protein production, such as the use of induction systems. For instance, tetracycline has been used to optimize the overexpression of glycosyltransferases under the control of the Tet on/off system in CHO cells, but unfortunately, a high expression of glycosyltransferases still led to growth inhibition [12]. Furthermore, interesting work using the same expression system has been conducted to control the overexpression of human transferrin (hTf) in human embryonic kidney (HEK-293) cells. That study found favorable concentrations of tetracycline at which the overexpression of hTf was optimal, but again, the high levels of expression limited the cell viability. Such impairment might have been a consequence of the overexpression of the protein of interest, which might have altered the quality of this cell product or even been toxic to the cells [13]. Some studies have attempted to investigate the effect of the expression of an ER-resident molecular chaperone, protein disulfide isomerase (PDI), on the specific production levels of thrombopoietin (TPO) and antibody (Ab) in Chinese hamster ovary cells. Mohan and colleagues used the Tet-off system (in the absence of tetracycline) to regulate PDI, TPO and $\mathrm{Ab}$ expression in $\mathrm{CHO}$ cells under doxycycline (DOX; a chemical analogue of tetracycline) induction. However, only a small increase in antibody production was observed, and the production of TPO was not affected by PDI expression [14].

Moreover, the optimization of protein production in $\mathrm{CHO}$ cells cultured at different temperatures has been addressed. For instance, lowering the temperature from $37^{\circ} \mathrm{C}$ to $33^{\circ} \mathrm{C}$ increased the production of erythropoietin (EPO) by approximately four-fold, but at the same time, a low cultivation temperature suppressed cell growth [15]. In addition, a temperature reduction from $37^{\circ} \mathrm{C}$ to $33^{\circ} \mathrm{C}$ in the culture of a $\mathrm{CHO}$ cell line producing recombinant human granulocyte/macrophage colony-stimulating factor (CHO-K1-hGM-CSF) led to a reduced growth rate, increased cell viability, improved cellular protein production and decreased cell metabolism [16]. One study on the optimization of protein production at $32^{\circ} \mathrm{C}$ also demonstrated that the specific growth rate of $\mathrm{CHO}$ cells producing human $\mathrm{mAb}$ decreased by $30-63 \%$ at $32^{\circ} \mathrm{C}$ compared to $37^{\circ} \mathrm{C}$. However, the specific antibody productivity of these cells was significantly enhanced at $32^{\circ} \mathrm{C}$ [17]. Lowering the cultivation temperature even more, from $37^{\circ} \mathrm{C}$ to $30^{\circ} \mathrm{C}$, caused growth arrest associated with a 1.7-fold increase in the specific production of secreted alkaline phosphatase (SEAP) in CHO cells [18].

In this context, we attempted to optimize the specific IgG productivity under different culture temperatures and by regulating the overexpression of apoptotic human protein $\mathrm{XBP}-1(\mathrm{~s})$ using the $\mathrm{T}^{-\mathrm{REx}^{\mathrm{Tm}}}$ system (Invitrogen, Carlsbad, CA, USA). The applied T-REx ${ }^{\mathrm{Tw}}$ system contains a regulatory plasmid (pcDNA6/TR), which encodes the tetracycline repressor, and an inducible expression plasmid (pcDNA ${ }^{\mathrm{m}} 4 / \mathrm{TO} / \mathrm{myc}-\mathrm{His} \mathrm{A}$ ) with a tetracycline inductor for expression of the gene of the interest $(x b p$ $1(s)$ ). Co-transfected together, these plasmids created a network to regulate XBP-1(s) expression under DOX induction. We cloned $x b p-1(s)$ into the T-REx ${ }^{\mathrm{m} x}$ system to control its expression with DOX. Then, we transfected the obtained T-REx ${ }^{\mathrm{m}}-\mathrm{XBP}-1$ (s) system into stably IgG-producing $\mathrm{CHO}$ cells and selected stable clones of this system expressing IgG-T-REx-XBP-1(s) to control specific IgG productivity under DOX induction (Figure 1). We determined the optimal concentration of DOX and the temperature at which IgG-T-REx-XBP-1(s) cells produced the maximal amount of IgG without a significant inhibition of cell growth. Moreover, cells treated with DOX for seven days recovered viable cell density to the level of non-treated cells after DOX was washed out from the cell system, and their specific IgG productivity dropped to the basal level. Furthermore, we studied the dependence of specific IgG productivity and viable cell density on the overexpression of XBP-1(s) and ER size expansion.

\section{Methods}

\section{Cell lines and media}

The CHO-K1 $\left(\mathrm{ATCC}^{\circ} \mathrm{CCL}-61^{\mathrm{Tm}}\right)$ and Raji (ATCC ${ }^{\circ} \mathrm{CCL}-$ $\left.86^{\mathrm{m}}\right)$ cell lines were purchased from American Type Culture Collection (ATCC, Manassas, VA, USA). CHO$\mathrm{K} 1$ cells were grown and maintained at $37^{\circ} \mathrm{C}$ or $30^{\circ} \mathrm{C}$ with $70 \%$ humidity and $5 \% \mathrm{CO}_{2}$ in HAM F12 media (Gibco, Big Cabin, OK, USA) supplemented with 2\% fetal bovine serum (FBS, Gibco, Big Cabin, OK, USA) and were used in experiments on protein production. Raji cells were grown and maintained at $37^{\circ} \mathrm{C}$ with70\% humidity and $5 \% \mathrm{CO}_{2}$ in RAMP media (Gibco, Big Cabin, OK, USA) supplemented with 10\% FBS and were used in FACS direct ligation experiments.

\section{Plasmids and cloning}

pCOMIRES HIL anti-CD20 is a tricistronic vector that encodes both the heavy and the light chains of an antiCD20 antibody along with a neomycin resistance gene under the control of a synthetic CMV promoter. This vector was transfected into $\mathrm{CHO}-\mathrm{K} 1$ cells to obtain IgG 


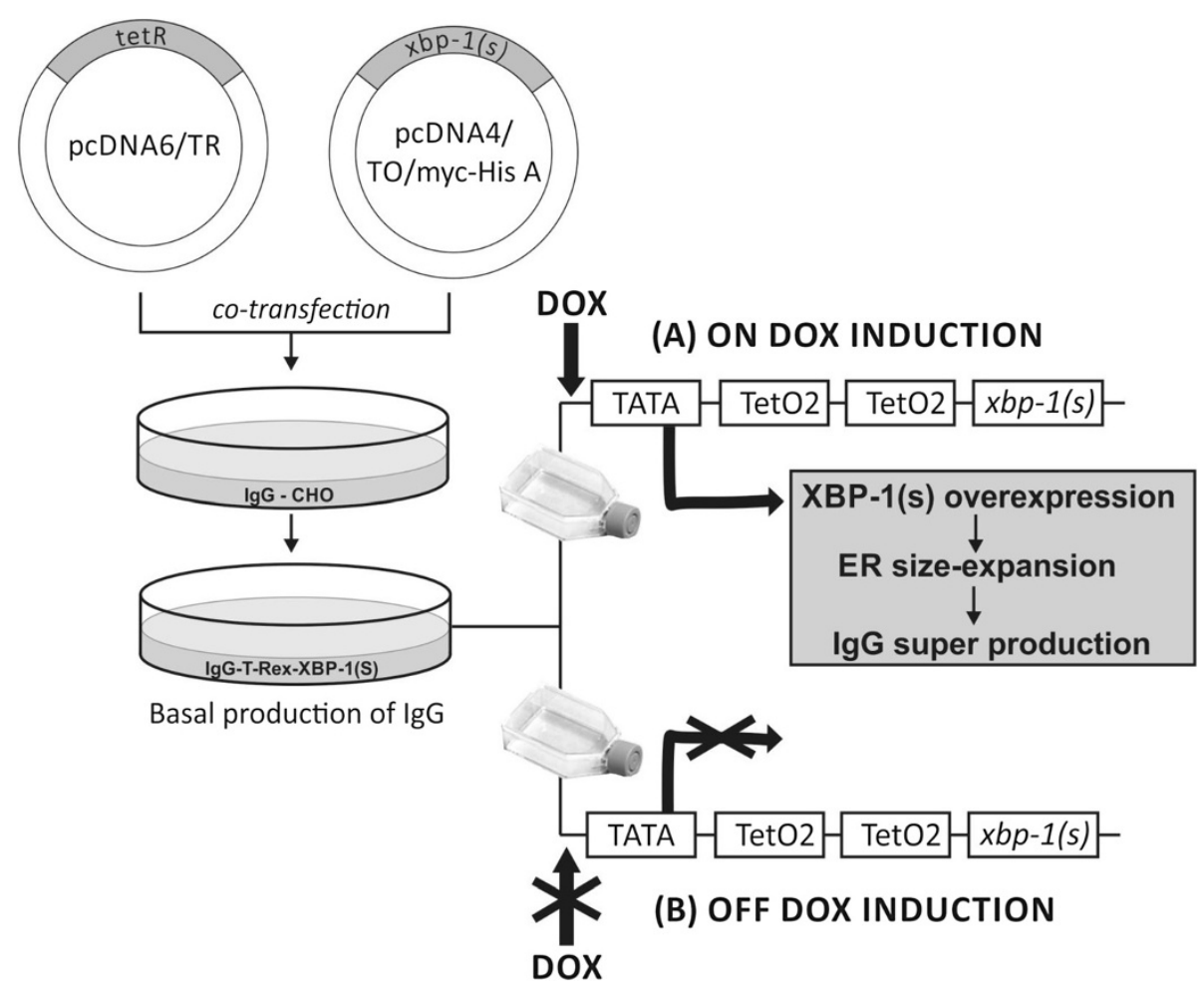

Figure 1 Schematic representation of the DOX-regulated T-Rex ${ }^{\mathrm{TM}}$ overexpression XBP-1(s) system. The overproduction of $\mathrm{IgG}$ as a result of the XBP-1(s) overexpression and ER size expansion under DOX induction (on DOX induction) (A). The repression of XBP-1(s) overexpression and ER size expansion resulted in the repression of overproduction of IgG in the absence of DOX (off DOX induction) (B).

(anti-CD20)-producing cells. The human $x b p-1(s)$ coding sequence was chemically synthesized by GeneScript (Piscataway, NJ, USA). The restriction enzymes Hind III and BamH I (Fermentas, Ontario, Canada) were used to obtain the $x b p-1(s)$ insert and then clone it into the inducible expression plasmid $\mathrm{pcDNA}^{\mathrm{rm}} 4 / \mathrm{TO} / \mathrm{myc}-\mathrm{His} \mathrm{A}$ from the Invitrogen T-REx ${ }^{\mathrm{Tm}}$ system (Invitrogen, Carlsbad, CA, USA). This plasmid was used to co-transfect IgG-producing stable clones of $\mathrm{CHO}$ cells along with the regulatory plasmid pcDNA6/TR (Invitrogen, Carlsbad, CA, USA). To confirm $x b p-1(s)$ cloning, XL1-blue bacterial cells (Stratagene, La Jolla, CA, USA) were transformed with ligated DNA. Ampicillin (Sigma, Ronkonkoma, NY, USA)-selected colonies were isolated and processed for DNA extraction and purification, which was performed using a QIAprep Miniprep Kit (Qiagen, Valencia, CA, USA). Restriction analysis and sequencing (using CMV forward primer 5' -CGCAAATGGGCGGTAGGCGTG-3' and $\mathrm{BGH}$ reverse primer $5^{\prime}$-TAGAAGGCACAGTCG AGG-3') confirmed the cloning of the $x b p-1(s)$ insert.

Transfection with pCOMIRES anti-CD20 DNA (IgG-encoding plasmid) into $\mathrm{CHO}$ cells and generation of stable IgG-producing cells

The transfection of pCOMIRES HIL anti-CD20 plasmid (encoding an anti-CD 20 (IgG) antibody, a secretable protein with molecular weight $150 \mathrm{kDa}$ (two light chains, each with molecular weight $25 \mathrm{kDa}$, and two heavy chains, each with molecular weight $50 \mathrm{kDa}$ )) into $\mathrm{CHO}$ cells was performed using a PolyPlus (JetPrime, New York, NY, USA) kit in six-well test plates (TPP, San Diego, CA, USA) according to the manufacturer's instructions. The clones harboring the pCOMIRES HIL anti-CD20 transgene were selected from a mixed population by the single-cell dilution method. Geneticin (Roche, Gaillard, France) was used for selection at $800 \mu \mathrm{g} / \mathrm{mL}$.

\section{Transfection with the T-REx ${ }^{\mathrm{TM}}-\mathrm{XBP}-1(\mathrm{~s})$ system into stable} IgG-producing clones of $\mathrm{CHO}$ cells and generation of stable double clones (IgG-T-REx-XBP-1(s) cells)

The co-transfection of T-REx- $x b p-1(s)$ plasmid (encoding a spliced form of human apoptotic XBP-1 protein with predicted molecular weight $40 \mathrm{kDa}$ ) along with regulatory plasmid pcDNA6/TR into one of the stable IgG-producing clones was performed using a PolyPlus (JetPrime, New York, NY, USA) kit according to the manufacturer's instructions in six-well test plates (TPP, San Diego, CA, USA). Blasticidin (Sigma, Ronkonkoma, NY, USA) and Zeocin (Sigma, Ronkonkoma, NY, USA) were added to a final concentration of $0.5 \mu \mathrm{g} / \mathrm{mL}$ and $50 \mu \mathrm{g} / \mathrm{mL}$, respectively. The selective markers encoded by regulatory plasmid pcDNA6/TR and expression plasmid pcDNA 4 / 
$\mathrm{TO} / \mathrm{myc}-\mathrm{His} \mathrm{A}$ are against blasticidin and Zeocin, respectively.

\section{Doxycycline induction}

Selected IgG-T-REx-XBP-1(s) cells (after the first transfection, IgG clones; after the second, co-transfection, T-REx-XBP-1(s) clones) were induced by DOX at different concentrations: $0 \mu \mathrm{g} / \mathrm{mL}$ for control, $0.1 \mu \mathrm{g} / \mathrm{mL}$, $0.5 \mu \mathrm{g} / \mathrm{mL}$ and $1 \mu \mathrm{g} / \mathrm{mL}$. We used these concentrations because we found out that $5 \mu \mathrm{g} / \mathrm{ml}$ and $7.5 \mu \mathrm{g} / \mathrm{ml}$ of doxycycline completely inhibits cells growth for clones and wild type $\mathrm{CHO}-\mathrm{K} 1$ cells. DOX induction was performed $24 \mathrm{hr}$ after IgG-T-REx-XBP-1(s) cells seeding at a uniform cell density $\left(0.5 \times 10^{5}\right.$ cells $\left./ \mathrm{mL}\right)$ in tissue culture flasks $\left(75 \mathrm{~cm}^{2}\right.$, TPP, San Diego, CA, USA) and then incubated for seven days at $37^{\circ} \mathrm{C}$ or $30^{\circ} \mathrm{C}$. All cultures reached at least $80 \%$ under these conditions. Samples were collected for viable cell density, Ab detection by ELISA, nuclear extract isolation and ER staining. Half of the cells in each group continued to grow for seven more days in DOX-free medium after DOX wash-out. Independently, IgG-T-REx-XBP-1(s) cells were incubated for 42 days at $30^{\circ} \mathrm{C}\left(150 \mathrm{~cm}^{2}\right.$ flasks, TPP, San Diego, CA, USA) with or without $1 \mu \mathrm{g} / \mathrm{mL}$ DOX. In all DOX induction experiments, DOX was added (at an appropriate concentration) every three days to the cell culture. Induction experiments were performed twice in duplicate (four independent culture samples per group).

\section{Viability assay}

The viable cell density of the IgG-T-REx-XBP-1(s) cells were tested under different DOX concentrations $(0 \mu \mathrm{g} /$ $\mathrm{mL}, 0.1 \mu \mathrm{g} / \mathrm{mL}, 0.5 \mu \mathrm{g} / \mathrm{mL}$ or $1 \mu \mathrm{g} / \mathrm{mL}$ ) every day during seven days of cell growth at $37^{\circ} \mathrm{C}$ and $30^{\circ} \mathrm{C}$. Seeding was performed at a uniform cell density $\left(0.06 \times 10^{5}\right.$ cells/ $\mathrm{mL}$ ) in six-well tissue culture plates (TPP, San Diego, CA, USA). At the seventh day all cultures reached at least $80 \%$ under these conditions. In addition, the viable cell density of IgG-T-REx-XBP-1(s) cells was tested on the seventh day of growth with DOX and on the seventh day after wash-out in DOX-free medium. In addition, IgG-T-REx-XBP-1(s) cells were tested every seventh day during 42 days of cell growth under $1 \mu \mathrm{g} / \mathrm{mL}$ DOX (or $0 \mu \mathrm{g} / \mathrm{mL}$ as control) at $30^{\circ} \mathrm{C}$. The viable cell density was measured using the trypan blue (Sigma, Ronkonkoma, NY, USA) exclusion method with a hemocytometer and light microscope for manual cell counting. Every viable cell density experiment was performed twice in duplicate (single determination from each of two independent culture samples per group in two independent experiments).

\section{ELISA}

The supernatants of IgG-T-REx-XBP-1(s) cells in the presence or absence of DOX were collected every seventh day of $37^{\circ} \mathrm{C}$ or $30^{\circ} \mathrm{C}$ growth for two weeks or every seventh day for six weeks and processed for analysis by enzymelinked immunosorbent assay (ELISA) (duplicate determination from each of two independent culture samples per group in two independent experiments). The Lunc/ Maxisorp Immunoplate (Thermo Scientific, Waltham, MA, USA) was incubated with primary antibody (goat anti-human IgG $(\mathrm{H}+\mathrm{L}), 1: 3000$ dilution; Thermo Scientific, Waltham, MA, USA) and blocked with $3 \%$ fat-free dehydrated milk solution. After blocking and washing the plate, the supernatants were applied to the plate and incubated for $2 \mathrm{hr}$. The plate was washed again, and secondary antibody (anti-human IgG Fc-specific, alkaline phosphatase-conjugated, produced in goat, 1:3000 dilution; Sigma, Ronkonkoma, NY, USA) was applied for $1 \mathrm{hr}$. The plate was washed again, and at the end of the procedure, the signal of absorbance was read at $405 \mathrm{~nm}$ by a microplate reader (ELx800 96-well Microplate Reader, MTX Lab Systems, Inc., Vienna, VA, USA) after 4-Nitrophenyl phosphate disodium salt solution (pNPP) (Invitrogen, Carlsbad, CA, USA) addition. In addition, human IgG (whole molecule; Thermo Scientific, Waltham, MA, USA) was used in different concentrations as a control on the same plate.

\section{Isolation and purification of produced proteins}

The IgG produced under different temperature conditions by IgG-T-REx-XBP-1(s) cells was purified on the HiTrap $^{\text {ma }}$ Protein A HP $1 \mathrm{~mL}$ (GE Life Sciences, Pittsburgh, PA, USA) column. The column was first equilibrated with $10 \mathrm{~mL}$ Protein A IgG Binding Buffer (Thermo Scientific, Waltham, MA, USA) at a rate of $1 \mathrm{~mL} / \mathrm{min}$. Then, the supernatant from IgG-T-REx-XBP1 (s) cells was applied to the equilibrated column. The column was washed with $30 \mathrm{~mL}$ Protein A IgG Binding Buffer (Thermo Scientific, Waltham, MA, USA). Then, the protein was eluted with $50 \mathrm{~mL}$ IgG Elution Buffer (Thermo Scientific, Waltham, MA, USA), and $2 \mathrm{~mL}$ per fraction was collected. Fractions were neutralized with Tris- $\mathrm{HCl} \mathrm{pH}$ 9.0. The $\mathrm{Ab}$ present in the fractions was immunodetected in a dot blot assay. Five microliters of each fraction was directly pipetted onto a nitrocellulose Hybond-C Extra membrane (Amersham ${ }^{\circ}$ Bioscience, Piscataway, NJ, USA). The membrane was blocked with $3 \%$ fat-free milk solution and incubated with anti-human IgG (Fc-specific, alkaline phosphatase-conjugated, produced in goat, 1:3000 dilution) (Sigma, Ronkonkoma, NY, USA), and the proteins were revealed using a BCIP/ NBT substrate Kit (Invitrogen, Carlsbad, CA, USA). The Ab-containing fractions were selected for dialysis, which was performed using a Centricon YM-50 (Amicon Bioseparations, Billerica, MA, USA) in PBS buffer (10 mM $\mathrm{NaH}_{2} \mathrm{PO}_{4}, 137 \mathrm{mM} \mathrm{NaCl}, 2.7 \mathrm{mM} \mathrm{KCl}, \mathrm{pH}$ 7.4). 


\section{Western blotting}

Anti-CD20 antibody was also detected by western blotting. Five hundred nanograms of IgG sample was loaded in each well of a Bis-Tris gel (NuPAGE ${ }^{\oplus}$ Novex $4-12 \%$ Bis-Tris Gel, Invitrogen, Carlsbad, CA, USA) and separated by sodium dodecyl sulfate-polyacrylamide gel electrophoresis (SDS-PAGE) according to the manufacturer's instructions. The proteins were transferred to the Hybond-C Extra nitrocellulose membrane (Amersham ${ }^{\circ}$ Bioscience, Piscataway, NJ, USA) and blocked in 3\% fat-free milk PBS solution. The immunodetection was performed using anti-human IgG (Fc-specific, alkaline phosphatase-conjugated, produced in goat (1:3000 dilution) (Sigma, Ronkonkoma, NY, USA) with a BCIP/ NBT substrate Kit ${ }^{\text {tm }}$ (Invitrogen, Carlsbad, CA, USA).

XBP-1(s) was also probed by western blotting. The nuclear extracts from the IgG-T-REx-XBP-1(s) cells were prepared as described by Becker and colleagues [10]. Briefly, the nuclear extracts were prepared from $5 \times 10^{6}$ cells/per sample and equal volumes of nuclear extracts were loaded into a Bis-Tris gel (NuPAGE ${ }^{\bullet}$ Novex 4-12\% Bis-Tris Gel, Invitrogen, Carlsbad, CA, USA), and SDSPAGE was performed according to the manufacturer's instructions. Samples were transferred to the Hybond-C Extra nitrocellulose membrane (Amersham ${ }^{\circ}$ Bioscience, Piscataway, NJ, USA), and after blocking with 3\% fat-free milk PBS solution, rabbit anti-human-XBP-1(s) (1:1000 dilution; Sigma, Ronkonkoma, NY, USA) was added, followed by alkaline phosphatase-conjugated anti-rabbit IgG incubation (1:1000 dilution; Sigma, Ronkonkoma, NY, USA). The proteins were revealed using a BCIP/NBT substrate $\mathrm{Kit}^{\text {tw }}$ (Invitrogen, Carlsbad, CA, USA).

\section{Fluorescence-activated cell sorting (FACS)-ER staining}

The IgG-T-REx-XBP-1(s) cells that were grown for seven days under DOX induction and those that were grown for one more week after wash-out were collected at $3 \times 10^{5}$ cells/per staining and washed with HBSS buffer $(140 \mathrm{mM} \mathrm{NaCl}, 4.7 \mathrm{mM} \mathrm{KCl}, 1 \mathrm{mM} \mathrm{MgCl}, 1.5 \mathrm{mM}$ $\mathrm{CaCl}_{2}, 10 \mathrm{mM}$ glucose, $10 \mathrm{mM}$ HEPES, $\mathrm{pH}$ 7.4). After washing with HBSS buffer, the cells were labeled with $250 \mathrm{nM}$ of ER-Tracker ${ }^{\mathrm{rm}}$ Green Dye (ER-Tracker ${ }^{\mathrm{Tm}}$ Green Dye for Live-Cell Endoplasmic Reticulum, Molecular Probes, Invitrogen, Carlsbad, CA, USA) according to the manufacturer's manual. The samples were washed again with HBSS buffer and analyzed using a BD FACS Verse flow cytometer (BD Bioscience, San Jose, CA, USA). Ten thousand events were collected per sample using no gate for acquisition. The dead cells were not excluded in the analysis. We used BD FACSuite to data acquisition. The experiment was performed twice in duplicate.

\section{FACS direct ligation assay}

Raji cells were grown for five passages as described above, collected and resuspended in 1 part RAMP media with $10 \%$ FBS and 1 part FACS buffer (PBS supplemented with $2 \% \mathrm{FBS}$ ) at $3 \times 10^{6}$ cells/well in a 96-well plate (TPP, San Diego, CA, USA). After centrifugation, the cells were blocked with FcR blocking reagent (MACS, Biotec, Bergisch Gladbach, Germany) on ice for 30 minutes according to the manufacturer's instructions. Purified and dialyzed IgG samples, which were produced by IgG-T-REx-XBP-1(s) cells at $37^{\circ} \mathrm{C}$ and $30^{\circ} \mathrm{C}$, and commercial IgG (rituximab, MabThera, Genetech Inc., South San Francisco, CA, USA) as a positive control were added at $100 \mathrm{ng}$ per well. Samples were incubated on ice for $1 \mathrm{hr}$ and centrifuged after the addition of FACS buffer. The cells were washed twice with FACS buffer and incubated with mouse FITC anti-human IgG (BD Pharmingen $^{\mathrm{Tw}}$, BD Biosciences, San Jose, CA, USA) according to the manufacturer's manual. The cells were incubated on ice for 30 minutes in the dark, washed again twice with FACS buffer and processed for fluorescence intensity measurements using a BD FACS Verse flow cytometer (BD Bioscience, San Jose, CA, USA). Each experiment was performed twice in duplicate.

\section{Results and discussion}

Viability and IgG production under induction with DOX in IgG-T-REx-XBP-1(s) cells cultivated at $37^{\circ} \mathrm{C}$ and $30^{\circ} \mathrm{C}$

To establish a DOX-regulated XBP-1(s) cell line, we first created stably IgG-producing clones of $\mathrm{CHO}$ cells by transfecting the pCOMIRES HIL anti-CD20 plasmid into $\mathrm{CHO}-\mathrm{K} 1$ cells. Then, IgG-CHO clones selected with $800 \mu \mathrm{g} / \mathrm{mL}$ of Geneticin were co-transfected with the T-REx-XBP-1(s) system and processed for second selection using $0.5 \mu \mathrm{g} / \mathrm{mL}$ of blasticidin and $50 \mu \mathrm{g} / \mathrm{mL}$ of Zeocin. From these double clones harboring both pCOMIRES HIL anti-CD20 and T-REx-XBP-1(s) system plasmids, we chose one out of 20 for DOX induction at different concentrations $(0 \mu \mathrm{g} / \mathrm{mL}$ (control), $0.1 \mu \mathrm{g} / \mathrm{mL}$, $0.5 \mu \mathrm{g} / \mathrm{mL}$ or $1 \mu \mathrm{g} / \mathrm{mL}$ ) and grew them at $37^{\circ} \mathrm{C}$ or $30^{\circ} \mathrm{C}$. Every day, cells were collected to monitor viable cell density. We found that the viable cell density of the IgG-T-REx-XBP-1(s) cells grown at $37^{\circ} \mathrm{C}$ under $1 \mu \mathrm{g} / \mathrm{mL}$ or $0.5 \mu \mathrm{g} / \mathrm{mL}$ DOX was slightly lower compared to the control and to the cells with $0.1 \mu \mathrm{g} / \mathrm{mL}$ DOX induction (Figure 2A). Moreover, the viable cell density of IgG-TREx-XBP-1(s) cells grown at $37^{\circ} \mathrm{C}$ without DOX or with $0.1 \mu \mathrm{g} / \mathrm{mL}$ DOX was 1.25 -fold higher compared to the cells grown at $30^{\circ} \mathrm{C}$ (Figure $2 \mathrm{~A}$ and $2 \mathrm{~B}$ ). These data agree with several previous studies [15-18]. Moreover, the viable cell density of IgG-T-REx-XBP-1(s) cells grown at $37^{\circ} \mathrm{C}$ under $1 \mu \mathrm{g} / \mathrm{mL}$ DOX induction was increased by $20.5 \%$ compared to cells incubated at $30^{\circ} \mathrm{C}$ under the same DOX concentration (Figure 2A and 2B). Thus, 


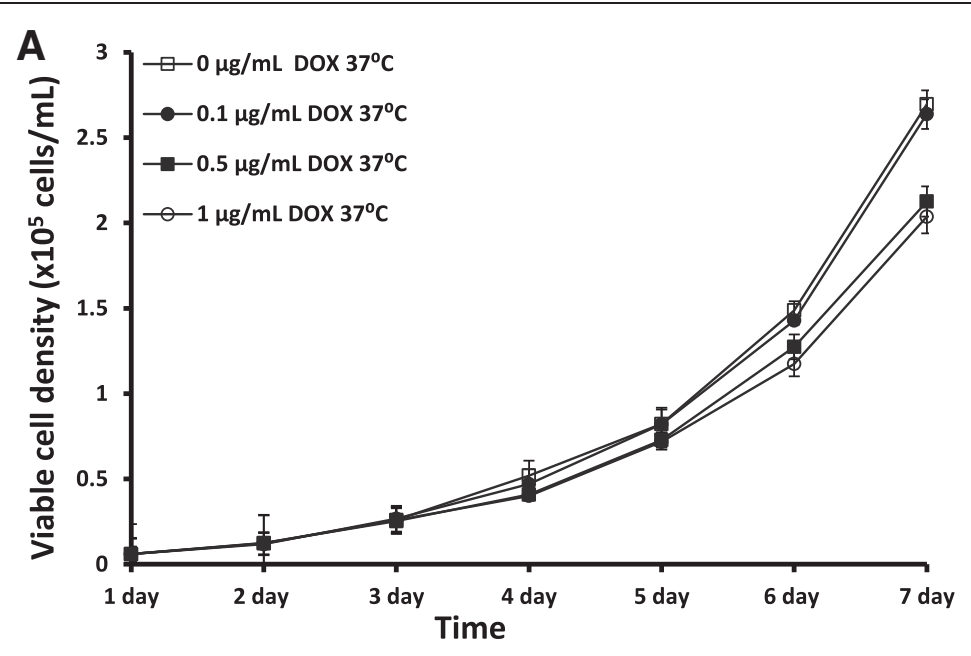

\section{B}
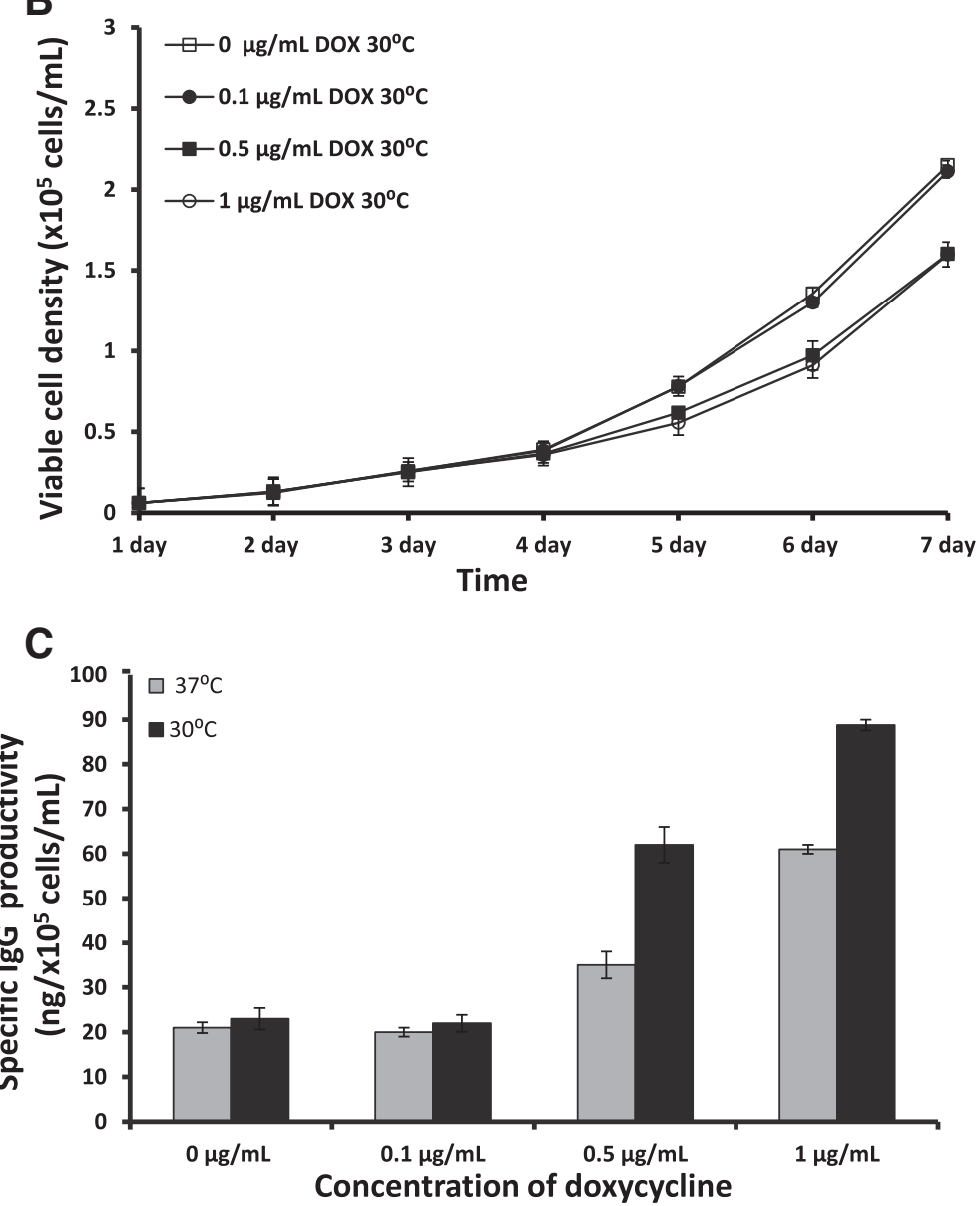

Figure 2 Viable cell density of IgG-T-Rex-XBP-1(s) cells cultured at $37^{\circ} \mathrm{C}(\mathrm{A})$ or $30^{\circ} \mathrm{C}(\mathrm{B})$ and their specific IgG productivity at $37^{\circ} \mathrm{C}$ and $30^{\circ} \mathrm{C}$ (C) under induction with $0 \mu \mathrm{g} / \mathrm{mL}$ (control), $0.1 \mu \mathrm{g} / \mathrm{mL}, 0.5 \mu \mathrm{g} / \mathrm{mL}$ and $1 \mu \mathrm{g} / \mathrm{mL}$ DOX. Error bars represent the standard deviation of the mean of two readings from each of two independent culture samples per group in two independent experiments, $n=4$.

IgG-T-REx-XBP-1(s) cells grew more slowly at $30^{\circ} \mathrm{C}$ with or without DOX compared to those at $37^{\circ} \mathrm{C}$.

The supernatants from all cells were collected after seven days of induction and tested by ELISA to determine their IgG yields. The specific IgG productivity depended on the concentration of DOX: under $0.5 \mu \mathrm{g} / \mathrm{mL}$ and $1 \mu \mathrm{g} /$ $\mathrm{mL}$ DOX, the increase of specific IgG productivity was $40 \%$ and $66 \%$, respectively, compared to the basal level of 
specific IgG productivity $\left(0\right.$ or $0.1 \mu \mathrm{g} / \mathrm{mL}$ DOX) at $37^{\circ} \mathrm{C}$ (Figure 2C). These data demonstrate that IgG-T-REx-XBP1 (s) cells produced three-fold more IgG compared to untreated cells, even at low viable cell density. At $0.1 \mu \mathrm{g} / \mathrm{mL}$ DOX, there was no improvement in specific IgG productivity at $37^{\circ} \mathrm{C}$. Moreover, the data from ELISA indicate that protein production in the cells incubated at $30^{\circ} \mathrm{C}$ increased four-fold and three-fold under $1 \mu \mathrm{g} / \mathrm{mL}$ and $0.5 \mu \mathrm{g} / \mathrm{mL}$ DOX, respectively. Once more, induction at a low concentration of DOX $(0.1 \mu \mathrm{g} / \mathrm{mL})$ did not increase specific IgG productivity at $30^{\circ} \mathrm{C}$, as above at $37^{\circ} \mathrm{C}$. In contrast, the specific IgG productivity by IgG-T-REx-XBP-1(s) cells at $30^{\circ} \mathrm{C}$ increased by $31.5 \%$ and $43.5 \%$ compared to induction at $37^{\circ} \mathrm{C}$ under $1 \mu \mathrm{g} / \mathrm{mL}$ and $0.5 \mu \mathrm{g} / \mathrm{mL}$ DOX concentrations, respectively (Figure $2 \mathrm{C}$ ). However, we did not detect any effect of low temperature on specific IgG productivity per se (without the induction of DOX). Tigges and Fussenegger [9] reported the same lack of effect in CHO cells expressing SEAP, whereas other authors reported an increase in the production of different proteins at low temperature and with no inductor [15-18]. These deviations in experimental results may be due to differences in the proteins and cell lines used in these studies. In conclusion, our data demonstrate a successful improvement of specific IgG productivity using $1 \mu \mathrm{g} / \mathrm{mL}$ DOX in IgG-T-REx-XBP-1(s) cells at $30^{\circ} \mathrm{C}$.

\section{Effect of XBP-1(s) expression and ER size expansion on protein production in IgG-T-REX-XBP-1(s) cells}

To test the hypothesis that XBP-1(s) expression and ER size expansion indirectly regulate protein production, IgG-T-REx-XBP-1(s) cells were incubated under different concentrations of DOX for seven days at $30^{\circ} \mathrm{C}$, and then the same cells were washed with DOX-free medium and incubated for seven more days at the same temperature in fresh DOX-free medium. The supernatant was collected before wash-out and after seven days of incubation in DOX-free medium and processed for ELISA. ELISA showed that specific IgG productivity by cells with DOX (first seven days) increased in a DOX concentrationdependent manner. The specific IgG productivity by cells incubated with $1 \mu \mathrm{g} / \mathrm{mL}$ DOX and $0.5 \mu \mathrm{g} / \mathrm{mL}$ DOX reached four-fold and three-fold that of the untreated cells (treated (t), Figure 3A). In addition, ELISA demonstrated that after DOX removal, the specific IgG productivity returned to the basal level (washed, (w) Figure 3A). Moreover, viability analysis indicated that the growth of the IgG-T-REx-XBP-1(s) cells under different concentrations of DOX was slightly inhibited (first seven days, treated ( $t$ ), Figure $3 \mathrm{~B}$ ) and then restored to the same level (washed $(\mathrm{w})$, Figure $3 \mathrm{~B}$ ) as cells that had never been exposed to DOX $(0 \mu \mathrm{g} / \mathrm{mL}$ (t or w), Figure 3B). In addition, IgG-TREx-XBP-1(s) cells were used to prepare nuclear extracts, which were analyzed by western blotting for the immune detection of XBP (s). Human XBP-1 (s) was overexpressed in a DOX concentration-dependent manner (first seven days, on DOX induction, treated (t) Figure 3C), but it was absent in cells that were washed and incubated in DOXfree medium for seven days (last seven days, off DOX induction, washed (w), Figure 3C).

ER expansion was also observed by flow cytometry. The fluorescence change of ER-Tracker ${ }^{\text {mat }}$ was used as a measure of ER size expansion. In this analysis, cell staining was more intense in samples treated with $1 \mu \mathrm{g} /$ $\mathrm{mL}$ or $0.5 \mu \mathrm{g} / \mathrm{mL}$ DOX for seven days (on DOX induction, treated $(\mathrm{t})$, Figure $4 \mathrm{~A}$ ) than in those treated with $0.1 \mu \mathrm{g} / \mathrm{mL}$ (on DOX induction, treated ( $\mathrm{t}$ ), Figure 4A) or $0 \mu \mathrm{g} / \mathrm{mL}$ or those that were washed out $(\mathrm{w})$, Figure 4B). Moreover, the signal from the washed out cells was equal among different conditions (off DOX induction, washed (w), Figure 4B), which indicated that DOX was responsible for a cascade of processes leading to ER size expansion. In addition, measurements of the median fluorescence intensity (MFI, Figure 4C) obtained from FACS analysis showed that the MFI of the cells treated with $1 \mu \mathrm{g} / \mathrm{mL}$ or $0.5 \mu \mathrm{g} / \mathrm{mL}$ DOX was 2.7 -fold or 1.85-fold higher, respectively, than the MFI of non-treated cells or washed out cells (Figure 4C). Thus, cells under DOX induction and low temperature grew more slowly but, at the same time, exhibited a greater increase in specific IgG productivity. Our data also demonstrate that the wash-out of DOX from the cells restored their viable cell density but reduced their specific IgG productivity to basal levels. Taken together, our results indicate the optimal conditions for specific IgG productivity under DOX induction. XBP-1(s) was overexpressed under induction with DOX, which led to the ER size expansion, and this resulted in an increase of specific IgG productivity/secretion. Our findings corroborate the data obtained by Tigges and Fussenegger, who reported an increased production of SEAP and SAMY under the expression of XBP-1(s) and the expansion of ER and Golgi [9].

\section{Binding activity of the recombinant proteins produced at different temperatures}

To assess its binding activity, the recombinant IgG produced by cells at different temperatures $\left(37^{\circ} \mathrm{C}\right.$ and $\left.30^{\circ} \mathrm{C}\right)$ was purified and tested for its ability to recognize CD20 at the cell surface of Raji cells that were subjected to flow cytometry analysis. FACS analysis indicated no significant difference in the binding activity of IgG produced by IgGT-REx-XBP-1(s) cells at different temperatures under DOX induction from commercial IgG (rituximab) (Figure 5A). Moreover, protein samples obtained from the IgG-T-RExXBP-1(s) cells at different temperatures under DOX induction were submitted to western blotting analysis, and the results did not suggest any differences in structural integrity 


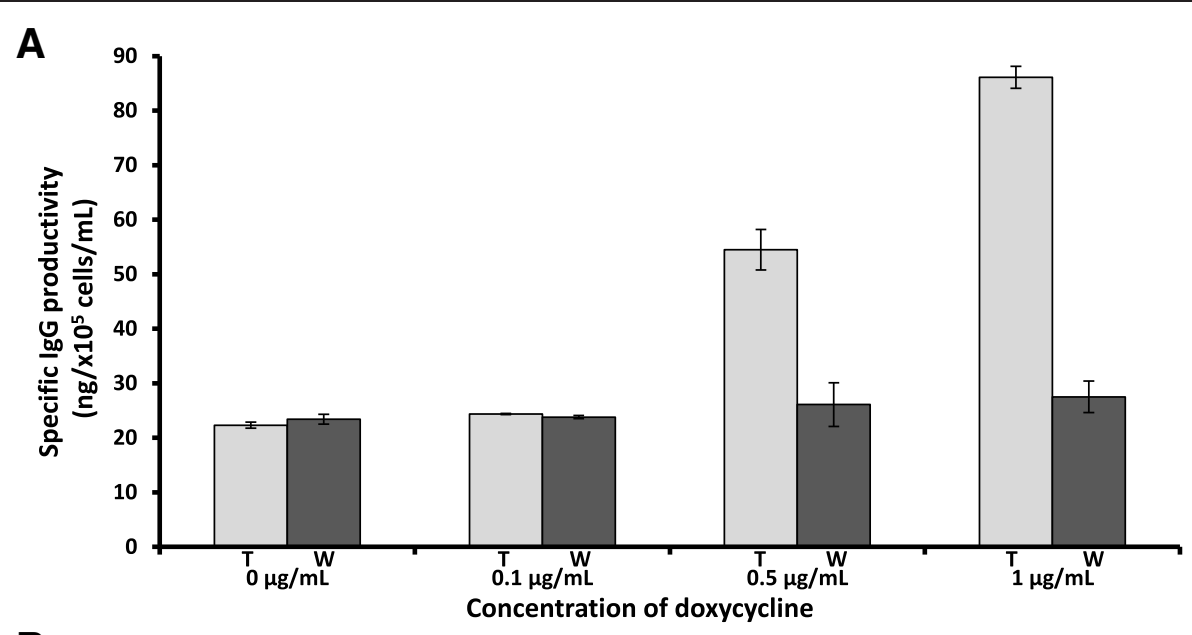

B

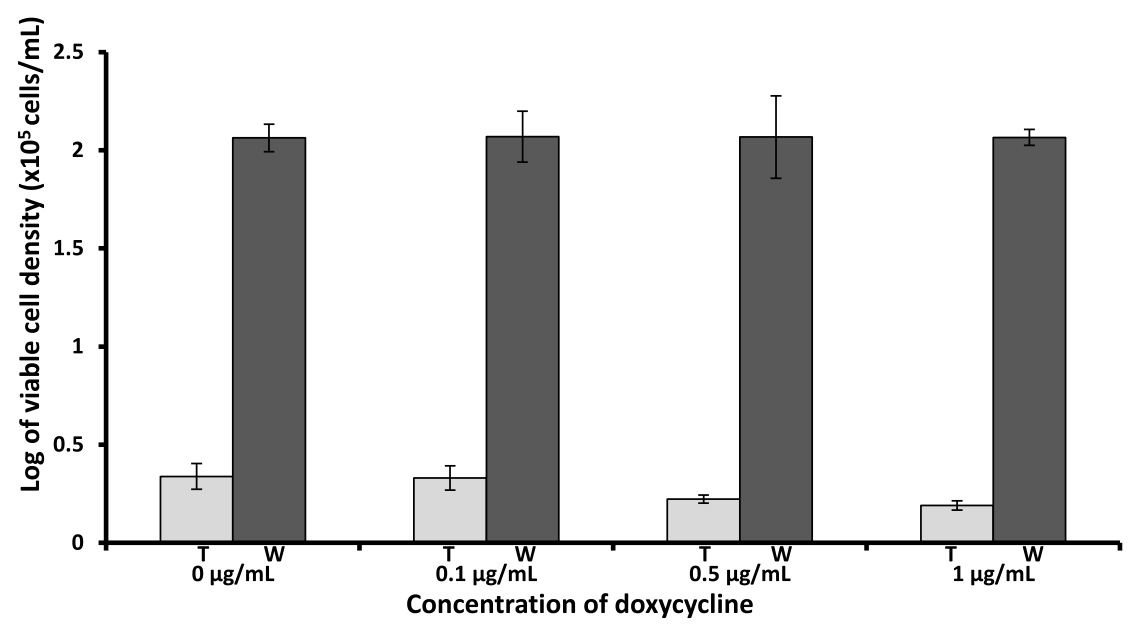

C

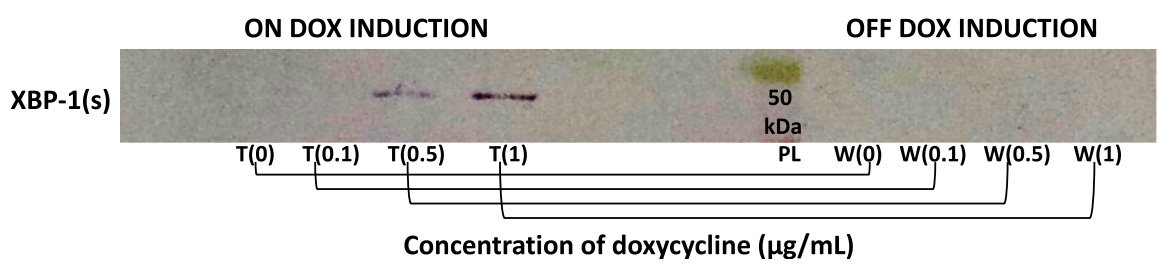

Figure 3 The specific lgG productivity (A), log of viable cell density (B) and western blot analysis of nuclear extracts (C) from the IgG-T-Rex-XBP-1(s) cells grown at $30^{\circ} \mathrm{C}$ under $0 \mu \mathrm{g} / \mathrm{mL}, 0.1 \mu \mathrm{g} / \mathrm{mL}, 0.5 \mu \mathrm{g} / \mathrm{mL}$ or $1 \mu \mathrm{g} / \mathrm{mL}$ DOX for seven days (treated, $t$ ) and from the same cells seven days after DOX wash-out (washed, w). PL, protein ladder. Error bars represent the standard deviation of the mean of double determination from each of two independent culture samples per group in two independent experiments, $n=4$.

of IgG produced at different temperatures (Figure 5B). These data support the use of low-temperature culture conditions under induction by DOX to increase protein production without eliminating the binding activity and structural integrity of the protein of interest.

\section{Establishing a stable protein-producing cell line}

To establish a stable cell line, IgG-T-REx-XBP-1(s) cells were seeded and grown at $30^{\circ} \mathrm{C}$ under $1 \mu \mathrm{g} / \mathrm{mL}$ DOX (or
$0 \mu \mathrm{g} / \mathrm{mL}$ DOX as control) for 42 days. The supernatant was collected every seventh day and submitted to ELISA, which showed stable specific IgG productivity around an average of $80.2 \mathrm{ng} / 10^{5}$ cells $/ \mathrm{mL}$ by cells incubated with DOX compared to the basal level $\left(25.7 \mathrm{ng} / 10^{5}\right.$ cells $/ \mathrm{mL}$ in cells without DOX) (Figure 6A). Moreover, the viable cell density of IgG-T-REx-XBP-1(s) cells under $1 \mu \mathrm{g} / \mathrm{mL}$ DOX was lower than cells without DOX for 42 days (Figure 6B), which allowed cells to be kept in the same 


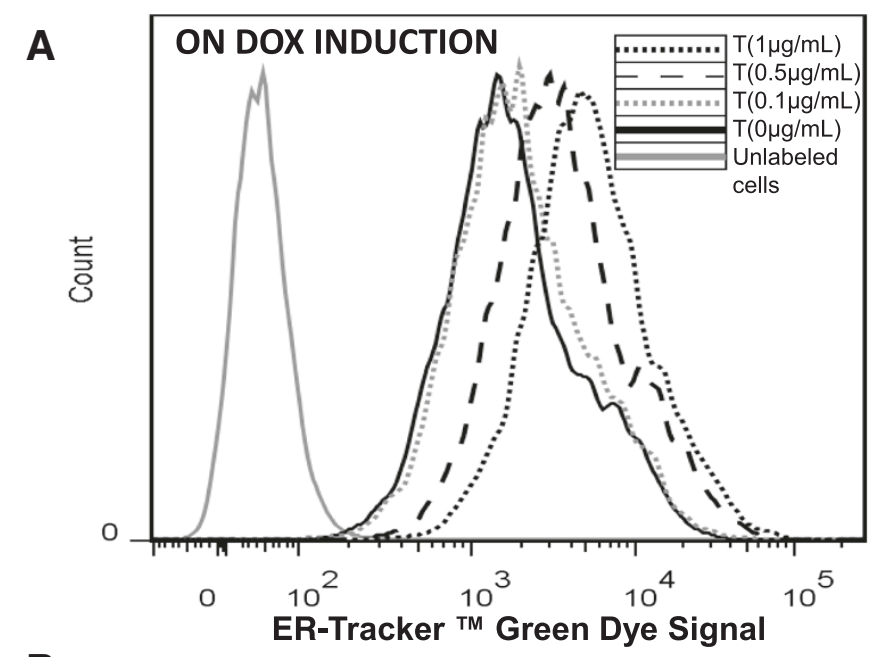

B
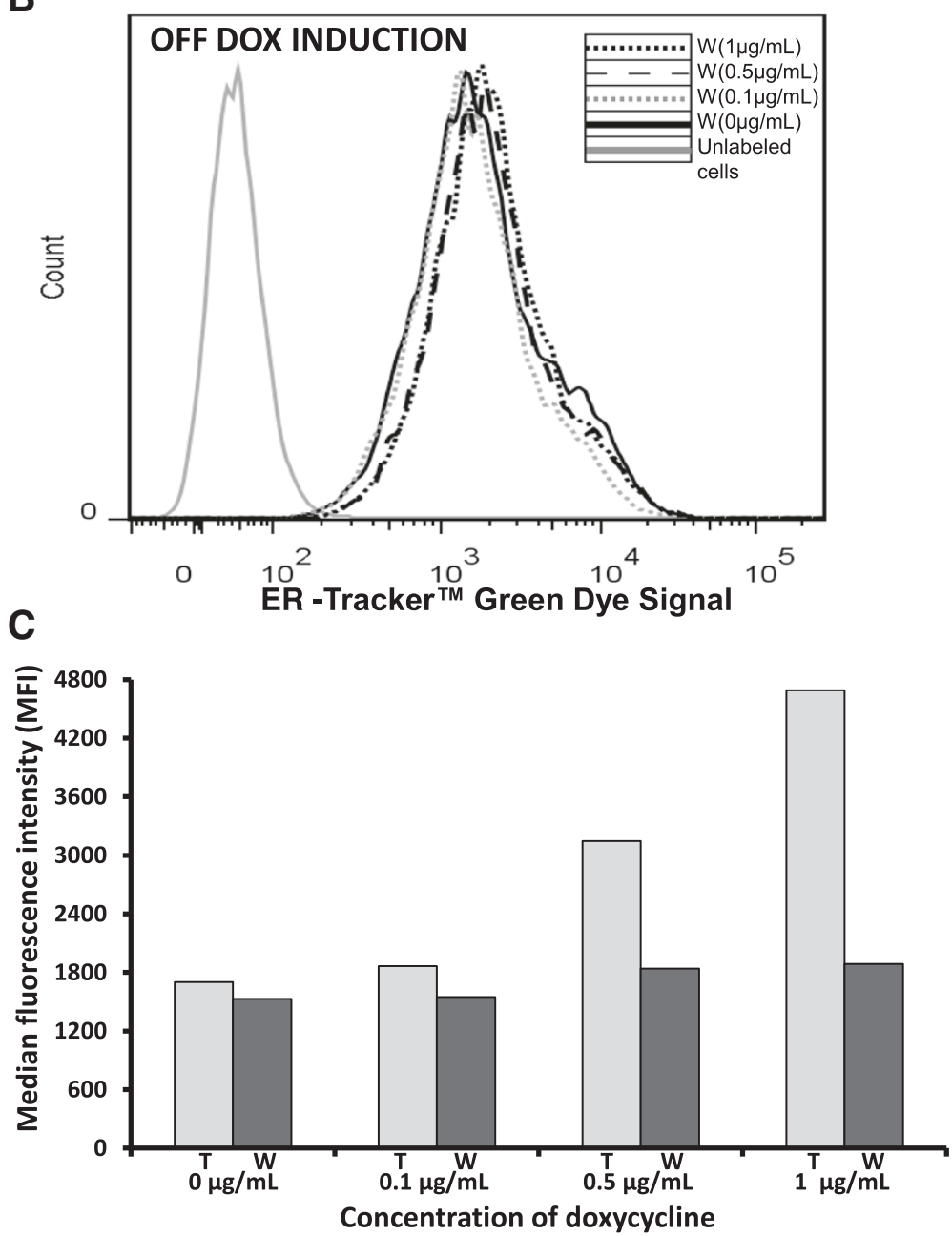

Figure 4 FACS analysis. The samples were run through the flow cytometer until 10.000 events were collected using no gate. The lgG-T-Rex-XBP-1(s) cells were grown under induction with $0 \mu \mathrm{g} / \mathrm{mL}, 0.1 \mu \mathrm{g} / \mathrm{mL}, 0.5 \mu \mathrm{g} / \mathrm{mL}$ or $1 \mu \mathrm{g} / \mathrm{mL}$ DOX (on DOX induction, treated (t)) for seven days at $30^{\circ} \mathrm{C}$. Then, cells from each group were washed with DOX-free media and grown in DOX-free media for seven more days at $30^{\circ} \mathrm{C}$ (off DOX induction, washed (w)). The cells from each group were stained with ER-tracker ${ }^{\mathrm{TM}}$ green dye, and cell counts vs. ER-Tracker ${ }^{\mathrm{TM}}$ signal from lgG-T-REX-XBP-1(s) cells were measured (on DOX induction, treated (t) (A) and off DOX induction, washed (W) (B)). Median fluorescence intensity (MFI) of ER-Tracker ${ }^{\mathrm{TM}} \mathrm{Green}$ Dye from

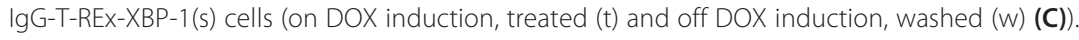



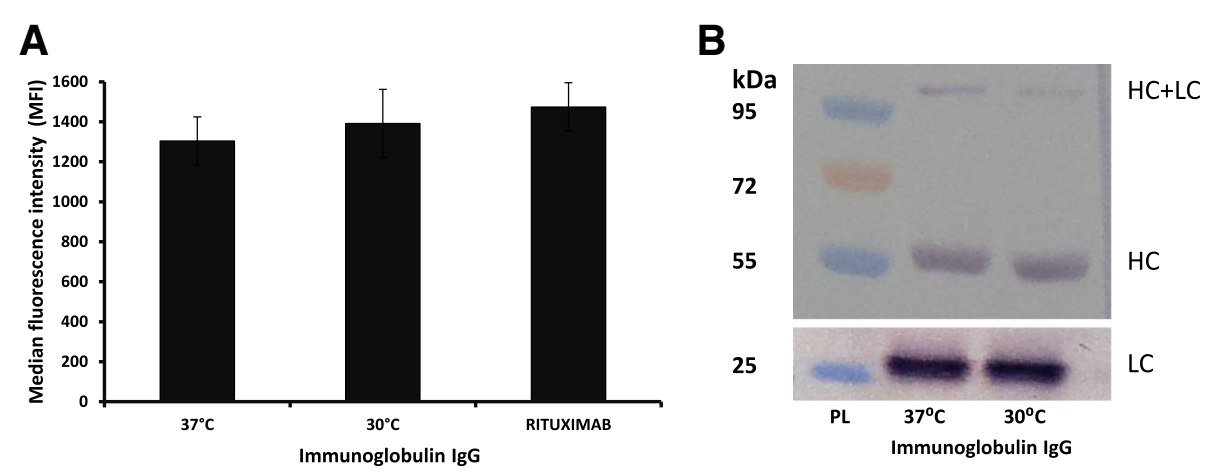

Figure 5 FACS and Western analyses. Median fluorescence intensity measurements of mouse FITC anti-human IgG ligated to the tested IgG (produced by lgG-T-REX-XBP-1(s) cells under DOX induction at $37^{\circ} \mathrm{C}$ and $30^{\circ} \mathrm{C}$ (and rituximab, control) that were previously incubated with Raji cells) (A). Western blot analysis of lgG produced by lgG-T-REX-XBP-1(s) cells at $37^{\circ} \mathrm{C}$ and $30^{\circ} \mathrm{C}$ under DOX induction (PL, protein ladder) (B).

culture flask without passaging to new flasks. The described approach might be useful for the production of recombinant secreted proteins, as cells growing under the combination of DOX induction and low temperature multiply more slowly but are more productive.

\section{Conclusion}

Many studies have been published on improving recombinant protein production. In general, the published data suggest that the optimization of the production of specific target proteins requires specifically adjusted growth

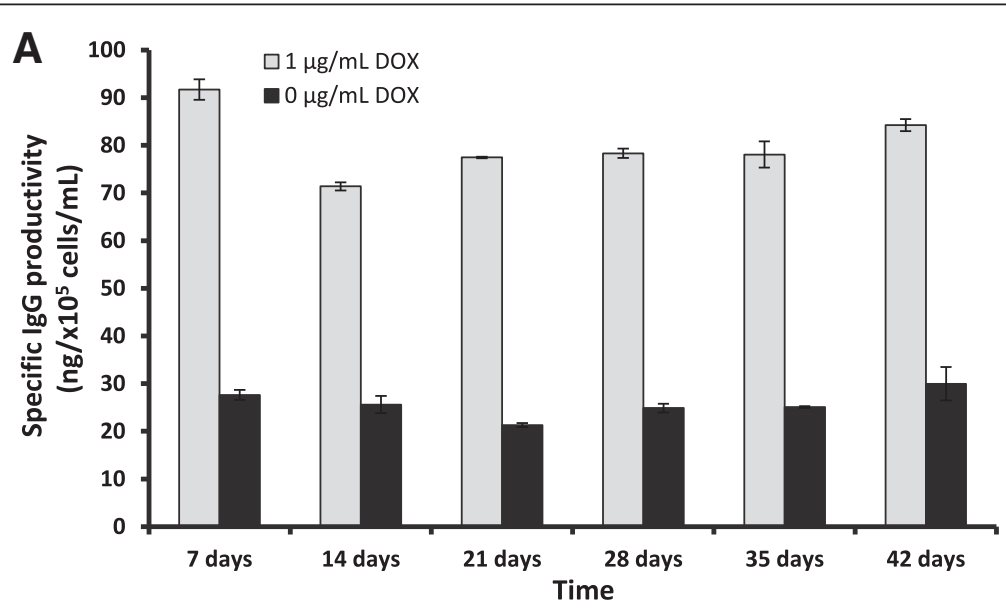

B

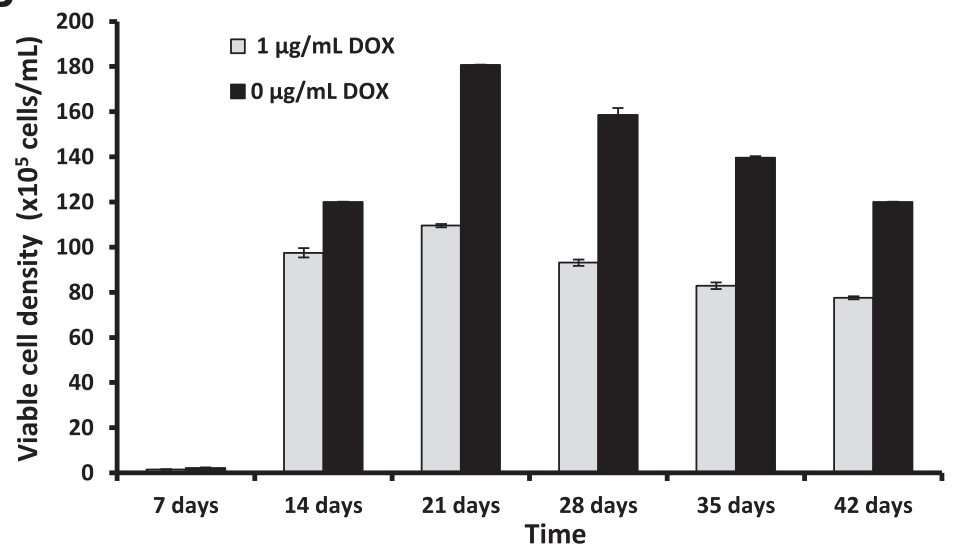

Figure 6 Specific IgG productivity (A) and viable cell density (B) of the lgG-T-REx-XBP-1(s) cells under $1 \mu \mathrm{g} / \mathrm{mL}$ DOX induction $(0 \mu \mathrm{g} / \mathrm{mL}$ DOX, control) for $\mathbf{4 2}$ days at $30^{\circ} \mathrm{C}$. Error bars represent the standard deviation of the mean of double determination from each of two independent culture samples per group in two independent experiments, $\mathrm{n}=4$. 
conditions and a carefully chosen cell line. In the present study, we optimized the conditions for IgG (human antiCD20) specific productivity in CHO-K1 cells. We showed that the combination of low temperature $\left(30^{\circ} \mathrm{C}\right)$ and XBP-1(s) overexpression regulated by DOX induction significantly improved anti-CD20 specific productivity: under $1 \mu \mathrm{g} / \mathrm{mL}$ DOX treatment, specific IgG productivity was increased by $32 \%$ compared to the cells grown under the same concentration at $37^{\circ} \mathrm{C}$ and $74 \%$ compared to the cells grown without DOX induction at $37^{\circ} \mathrm{C}$ or $30^{\circ} \mathrm{C}$. Moreover, the results of our study indicate the direct dependence of specific IgG productivity on the concentration of DOX (under $0.5 \mu \mathrm{g} / \mathrm{mL}$, the increase was 2.7 fold, and under $1 \mu \mathrm{g} / \mathrm{mL}$, the increase was 3.9-fold), which allows for the precise regulation of specific IgG productivity in $\mathrm{CHO}-\mathrm{K} 1$ cells. In addition to the concentration dependence, we demonstrated the possibility of returning the specific IgG over productivity to the basal level of specific productivity by removing DOX. This step also restored the viable cell density, which permitted the cells to overcome the problem of accumulation of the target protein. In the production of proteins, it may be possible to use the T-Rex-XBP-1(s) system to turn up and down the production of protein, repeating this cycle several times to accumulate higher amounts of target protein without a loss of cell viability. We also observed a DOX concentration-dependent relationship involving XBP-1(s) overexpression (western analysis), ER size expansion (FACS measurements) and specific IgG productivity (ELISA). Finally, our data demonstrate that it is possible, under DOX induction at low temperature, to produce a target protein for an extended period of time. Taken together, our data suggest the T-REx-XBP-1(s) system can be used in CHO-K1 cells for human immunoglobulin production.

\begin{abstract}
Abbreviations
Ab: Antibody; bcl-2: B-cell lymphoma protein 2; bcl-XL: B-cell lymphoma-extra-large protein; $\mathrm{CHO}-\mathrm{K} 1$ : Chinese hamster ovary cells; CHO-K1-hGM-CSF: CHO cell line producing recombinant human granulocyte/ macrophage colony-stimulating factor; DOX: Doxycycline; ELISA: Enzyme-linked immunosorbent assay; EPO: Erythropoietin; ER: Endoplasmic reticulum; FACS: Fluorescence-activated cell sorting; HEK-293: Human embryonic kidney cells 293; HSP70: Heat shock proteins 70; hTf: Human transferrin; IgG: Human immunoglobulin G; mAbs: Monoclonal antibodies; MFI: Median fluorescence intensity; PDI: Protein disulfide isomerase; pNPP: 4-Nitrophenyl phosphate disodium salt solution; SAMY: alpha-amylase; SEAP: Secreted alkaline phosphatase proteins; SDS-PAGE: Sodium dodecyl sulfate-polyacrylamide gel electrophoresis; Tet: Tetracycline; TPO: Thrombopoietin; UPR: Unfolded protein response; XBP-(s): Spliced form of human X-box binding protein.
\end{abstract}

\section{Competing interests}

The authors declare that they have no competing interests.

\section{Authors' contributions}

$G G, A Q M$ and $M M B$ designed the study, interpreted the results and wrote the manuscript. GG, KCRS and RRT performed the experiments and interpreted the results. All authors read and approved the final manuscript.

\section{Acknowledgments}

The work was funded by grant from BNDES, Brazil. GG is a fellow of PNPD postdoctoral program from CAPES. KCRS is a fellow of the CAPES graduate program.

Received: 23 December 2013 Accepted: 8 April 2014

Published: 11 April 2014

\section{References}

1. Costa AR, Rodrigues ME, Henriques M, Azeredo J, Oliveira R: Guidelines to cell engineering for monoclonal antibody production. Eur J Pharm Biopharm 2010, 74:127-138.

2. Frenzel $A$, Hust M, Schirrmann T: Expression of recombinant antibodies. Front Immunol 2013, 4(217):1-20.

3. Fussenegger M, Fassnacht D, Schwartz R, Zanghi JA, Graf M, Bailey JE, Pörtner R: Regulated overexpression of the survival factor bcl-2 in $\mathrm{CHO}$ cells increases viable cell density in batch culture and decreases DNA release in extended fixed-bed cultivation. Cytotechnology 2000, 32(1):45-61.

4. Itoh Y, Ueda H, Suzuki E: Overexpression of bcl-2, apoptosis suppressing gene: Prolonged viable culture period of hybridoma and enhanced antibody production. Biotechnol Bioeng 1995, 48(2):118-122.

5. Meents $\mathrm{H}$, Enenkel B, Eppenberger HM, Werner RG, Fussenegger M: Impact of coexpression and coamplification of sICAM and antiapoptosis determinants bcl-2/bcl-x (L) on productivity, cell survival, and mitochondria number in CHO-DG44 grown in suspension and serum-free media. Biotechnol Bioeng 2002, 80(6):706-716.

6. Sauerwald TM, Betenbaugh MJ, Oyler GA: Inhibiting apoptosis in mammalian cell culture using the caspase inhibitor XIAP and deletion mutants. Biotechnol Bioeng 2002, 77(6):704-716.

7. Lasunskaia EB, Fridlianskaia II, Darieva ZA, da Silva MS, Kanashiro MM, Margulis BA: Transfection of NSO myeloma fusion partner cells with HSP70 gene results in higher hybridoma yield by improving cellular resistance to apoptosis. Biotechnol Bioeng 2003, 81(4):496-504.

8. Shaffer AL, Shapiro-Shelef M, Iwakoshi NN, Lee AH, Qian SB, Zhao H, Yu X, Yang L, Tan BK, Rosenwald A, Hurt EM, Petroulakis E, Sonenberg N, Yewdell JW, Calame K, Glimcher LH, Staudt LM: XBP1, downstream of Blimp-1, expands the secretory apparatus and other organelles, and increases protein synthesis in plasma cell differentiation. Immunity 2004, 21(1):81-93.

9. Tigges M, Fussenegger M: Xbp1-based engineering of secretory capacity enhances the productivity of Chinese hamster ovary cells. Metab Eng 2006, 8(3):264-272.

10. Becker E, Florin L, Pfizenmaier K, Kaufmann H: An XBP-1(s) dependent bottle-neck in production of IgG subtype antibodies in chemically defined serum-free Chinese hamster ovary $(\mathrm{CHO})$ fed-batch processes. J Biotechnol 2008, 135(2):217-223.

11. Becker E, Florin L, Pfizenmaier K, Kaufmann H: Evaluation of a combinatorial cell engineering approach to overcome apoptotic effects in XBP-1(s) expressing cells. J Biotechno/ 2010, 146(4):198-206.

12. Umaña P, Jean-Mairet J, Bailey JE: Tetracycline-regulated overexpression of glycosyltransferases in Chinese hamster ovary cells. Biotechnol Bioeng 1999, 65(5):542-549.

13. Jones J, Nivitchanyong T, Giblin C, Ciccarone V, Judd D, Gorfien S, Krag SS, Betenbaugh MJ: Optimization of tetracycline-responsive recombinant protein production and effect on cell growth and ER stress in mammalian cells. Biotechnol Bioeng 2005, 91(6):722-732.

14. Mohan C, Park SH, Chung JY, Lee GM: Effect of doxycycline-regulated protein disulfide isomerase expression on the specific productivity of recombinant $\mathrm{CHO}$ cells: thrombopoietin and antibody. Biotechnol Bioeng 2007, 98(3):611-615.

15. Yoon SK, Song JY, Lee GM: Effect of low culture temperature on specific productivity, transcription level, and heterogeneity of erythropoietin in Chinese hamster ovary cells. Biotechnol Bioeng 2003, 82(3):289-298.

16. Bollati-Fogolín M, Forno G, Nimtz M, Conradt H, Etcheverrigaray M, Kratje R: Temperature reduction in cultures of hGM-CSF-expressing CHO cells: effect on productivity and product quality. Biotechnol Prog 2005, 21(1):17-21. 
17. Yoon SK, Hwang SO, Lee GM: Enhancing effect of low culture temperature on specific antibody productivity of recombinant Chinese hamster ovary cells: clonal variation. Biotechnol Prog 2004, 20(6):1683-1688

18. Kaufmann H, Mazur X, Fussenegger M, Bailey J: Influence of low temperature on productivity, proteome and protein phosphorylation of CHO cells. Biotechnol Bioeng 1999, 63(5):573-582.

doi:10.1186/1472-6750-14-26

Cite this article as: Gulis et al:: Optimization of heterologous protein production in Chinese hamster ovary cells under overexpression of spliced form of human X-box binding protein. BMC Biotechnology 2014 14:26.

\section{Submit your next manuscript to BioMed Central and take full advantage of:}

- Convenient online submission

- Thorough peer review

- No space constraints or color figure charges

- Immediate publication on acceptance

- Inclusion in PubMed, CAS, Scopus and Google Scholar

- Research which is freely available for redistribution 